\author{
Military Technical College \\ Kobry El-Kobbah, \\ Cairo, Egypt
}

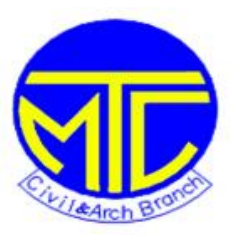

$9^{\text {th }}$ International Conference
on Civil and Architecture
Engineering
ICCAE-9-2012

\title{
Modelling of RC Slabs at High Temperature Using Simplified Grillage Model
}

\begin{abstract}
Sanad, Abdel Moniem*
Abstract

Modelling of full scale fire tests has led to new understanding of the behaviour of structures under fire conditions. Much of this understanding has come from parametric analysis using different finite element models. Outcome of each model depends on the assumptions adopted in the structures idealization. Recent research es showed that behaviour of indeterminate structures at high temperature changes drastically from its behaviour at ambient temperature and large deflections experienced in real buildings during fire a re due to restrained thermal expansion of steel members. However, slabs are the largest elements in any building and it is expected to play a major role in distributing the applied load and contributing to the stability of structures. Modelling of concrete slab at high temperature has been the subject of several researches with different advantages for each model. This paper describes a grillage slab model used to idealize the concrete slab at high temperature. This simplified model has the advantage of ide ntifying the function of slab at high temperature and providing a clear understanding of its contribution to the global stability of structure during fire Finally the comparison of the developed models and experimental results show a good agreement.
\end{abstract}

\section{Keywords}

Concrete Slab, Numerical Modelling, Finite Element Method, Full Scale Fire Test, Composite Floor. 
* Associate Professor and Chairman of Construction and Building Eng. Dept., Arab Academy for Science and Technology and Maritime Transport, Cairo

\section{Introduction}

Understanding the behaviour of different structural elements during fire i s essential to safely design buildings that can resist fire for a defined duration. Buildings are classified according to their use and importance; each has to withstand fire for enough time to allow fire fighters to extinguish the fire and safely evacuate people before any collapse. Following several fire disasters, the assessment of structures stability and behaviour of individual elements have been the focus of many research projects in fire safety over the last 2 decades [18]. Large full scale experimental works [1] and finite element modelling [17] were conducted to understand the real effect of fire on building.

In typical construction system, slabs, beams and columns distribute the applied load from each level to the ground through foundation. Their behaviour at high-temperature depends on their strength, duration and variation of heating regime with time and spac e [10,16]. At ambient temperature, slabs are two dimension al elements subjected to applied transverse loads. They transmit the applied loads to beams through bending, shear and normal forces. However at high-temperature, thermal expansion of concrete slabs exposed to fire against surrounding floor creates new horizontal forces in the slab. The significance of the temperature field and the way it influences the structure are crucial for developing safe structural design. There are two main effects of heating in a structural member, thermal expansion caused by an average rise in temperature, and thermal bowing caused by a non uniform distribution of temperature over the depth of the member. Both of these actions impose thermal strains; longitudinal extension in case of expansion and curvature as a result of thermal bowing. However if these thermal strains are restrained, the result is the development of mechanical strains in the opposite sense of the thermal strains thus reducing the total strains and therefore displacements, giving rise to large forces, most commonly axial compressions and hogging moments. However if the gradients are large enough axial tensions can also developed.

This paper presents the development of simplified model for concrete slabs exposed to fire based on the modelling of the slab orthotropic behaviour by two separate slab responses in the longitudinal and transverse directions using a grillage representation. This slab model is implemented in a larger finite element model to simulate the behaviour of two full scale fire tests. It reproduces all the phenomena occurring during fire and has the advantage of providing a description of the complex behaviour in a relatively simplified context.

\section{Geometric description}

\section{Layout}

The flooring system studied in this paper is composed of concrete slab casted over steel deck and connected to steel joists using shear studs. The slab was cast in -situ on profiled steel decking and had a total thickness of $130 \mathrm{~mm}$. Slabs have ribs in the short direction spanning between secondary beams. At ambient temperature, the slab distributes the load in the short 
direction and it mainly behaves in one way direction as shown in Figure 1. Secondary beams are connected to primary beams or directly to steel columns. Slab main reinforcement consists of the steel deck of $0.9 \mathrm{~mm}$ thickness [9]. A reinforcement mesh of $142 \mathrm{~mm}^{2}$ is also provided as secondary reinforcement to resist cracking and bridges over the secondary beams in the negative (hogging) bending zones as shown in Figure 2. Several compartments were built on the described slab, with variable area and locations. Their objective was to confine each fire test to a pre-defined zone of the floor. Several fire tests were carried out and all tests were fully instrumented with temperature probes, extensometers and strain gauges respectively. Two tests are used in this paper to validate the slab model developed viz .: Fire Test 1 and Fire Test3 (see Fig. 1).

Test 1 was constructed on the seventh floor. This fire test was designed to study the behaviour of a secondary beam spanning between two steel columns. The beam was surro unded by a gas fired furnace but the columns and connections were left outside. The furnace was $8 \mathrm{~m}$ long $\mathrm{x}$

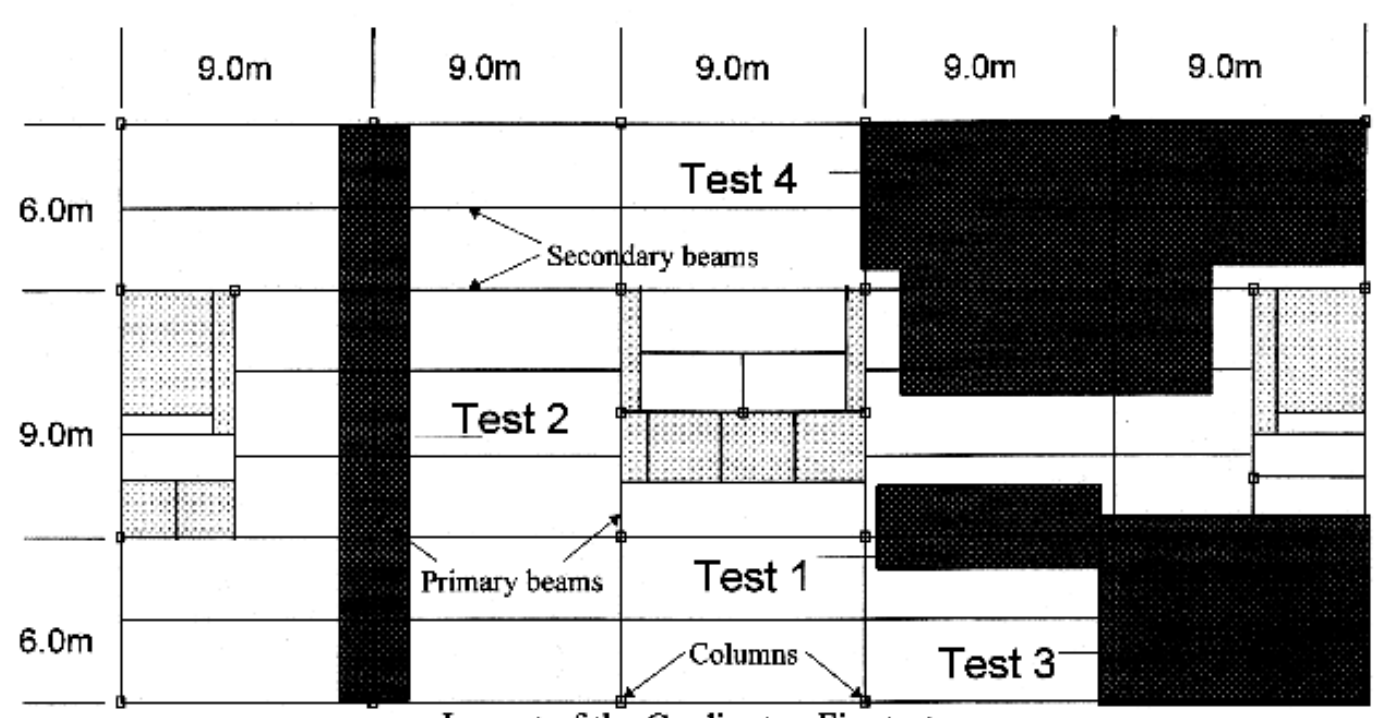

Layout of the Cardington Fire tests

Figure 1 - Layout of composite floor 


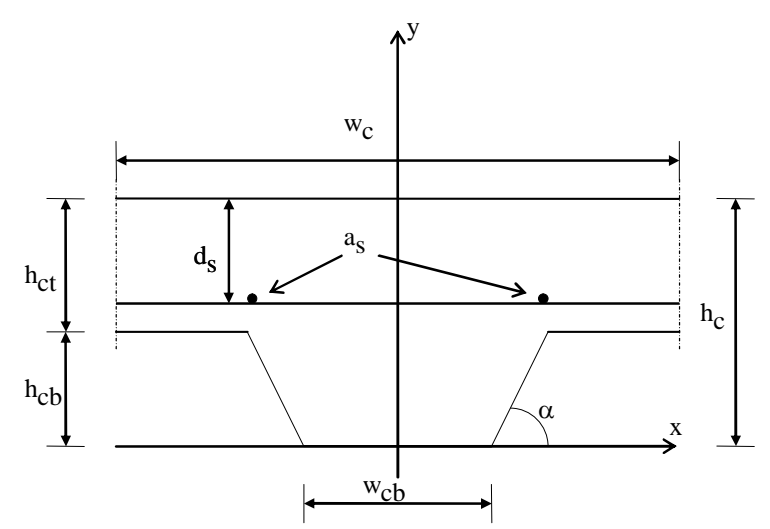

Figure 2 - Cross section of the composite slab

Table 1 - Dimensions of slab sections

\begin{tabular}{|l|c|c|c|c|c|c|c|}
\hline & $\begin{array}{l}\mathrm{W}_{\mathrm{c}} \\
(\mathrm{mm})\end{array}$ & $\begin{array}{l}\mathrm{W}_{\mathrm{cb}} \\
(\mathrm{mm})\end{array}$ & $\begin{array}{l}\mathrm{h}_{\mathrm{ct}} \\
(\mathrm{mm})\end{array}$ & $\begin{array}{l}\mathrm{h}_{\mathrm{cb}} \\
(\mathrm{mm})\end{array}$ & $\alpha^{\circ}$ & $\begin{array}{c}\mathrm{a}_{\mathrm{s}} \\
\left(\mathrm{mm}^{2}\right)\end{array}$ & $\mathrm{d}_{\mathrm{s}}(\mathrm{mm})$ \\
\hline Slab in transverse direction & $\mathbf{3 0 0}$ & $\mathbf{1 3 6}$ & $\mathbf{7 0}$ & $\mathbf{6 0}$ & $\mathbf{6 5}$ & $\mathbf{4 2 . 6}$ & $\mathbf{5 5}$ \\
\hline Slab in longitudinal direction & $\mathbf{2 2 5 0}$ & - & $\mathbf{7 0}$ & - & - & $\mathbf{3 1 9 . 5}$ & $\mathbf{5 5}$ \\
\hline
\end{tabular}

$3 \mathrm{~m}$ wide $\mathrm{x} 2 \mathrm{~m}$ high; insulated with mineral wool and ceramic fibre. The heating regime was between $3^{\circ} \mathrm{C} / \mathrm{min}-10^{\circ} \mathrm{C} / \mathrm{min}$ until temperatures of $800^{\circ} \mathrm{C}-900^{\circ} \mathrm{C}$ were achieved.

In Test 3 , the compartment was approximately $80 \mathrm{~m}^{2}$ and built on the first floor in one corner of the building. To achieve the required level of thermal loading (around $1000^{\circ} \mathrm{C}$ ), a real fire was created, with a fire loading of $45 \mathrm{~kg}$ of $\operatorname{wood} / \mathrm{m}^{2}$ and the ventilation was provided by an adjustable $7 \mathrm{~m}$ wide opening. The tested floor contains 4 unprotected beams and 2 protected edge steel beams. All secondary beams are equally spaced and have $9 \mathrm{~m}$ span connected semirigidly to columns or to primary beams. The heated primary beam has a length of $6 \mathrm{~m}$. All steel columns were protected along their full height, Figure 1 shows the layout of the test.

\section{Discretization of concrete slab}

\section{Grillage model of slab}


The finite element model used in this study was developed by Sanad et al. [12] using the commercial software ABAQUS [1]. For each fire test, the area affected by the fire is heated according to the measured temperature.

Figure 3 shows the finite element model of half floor.

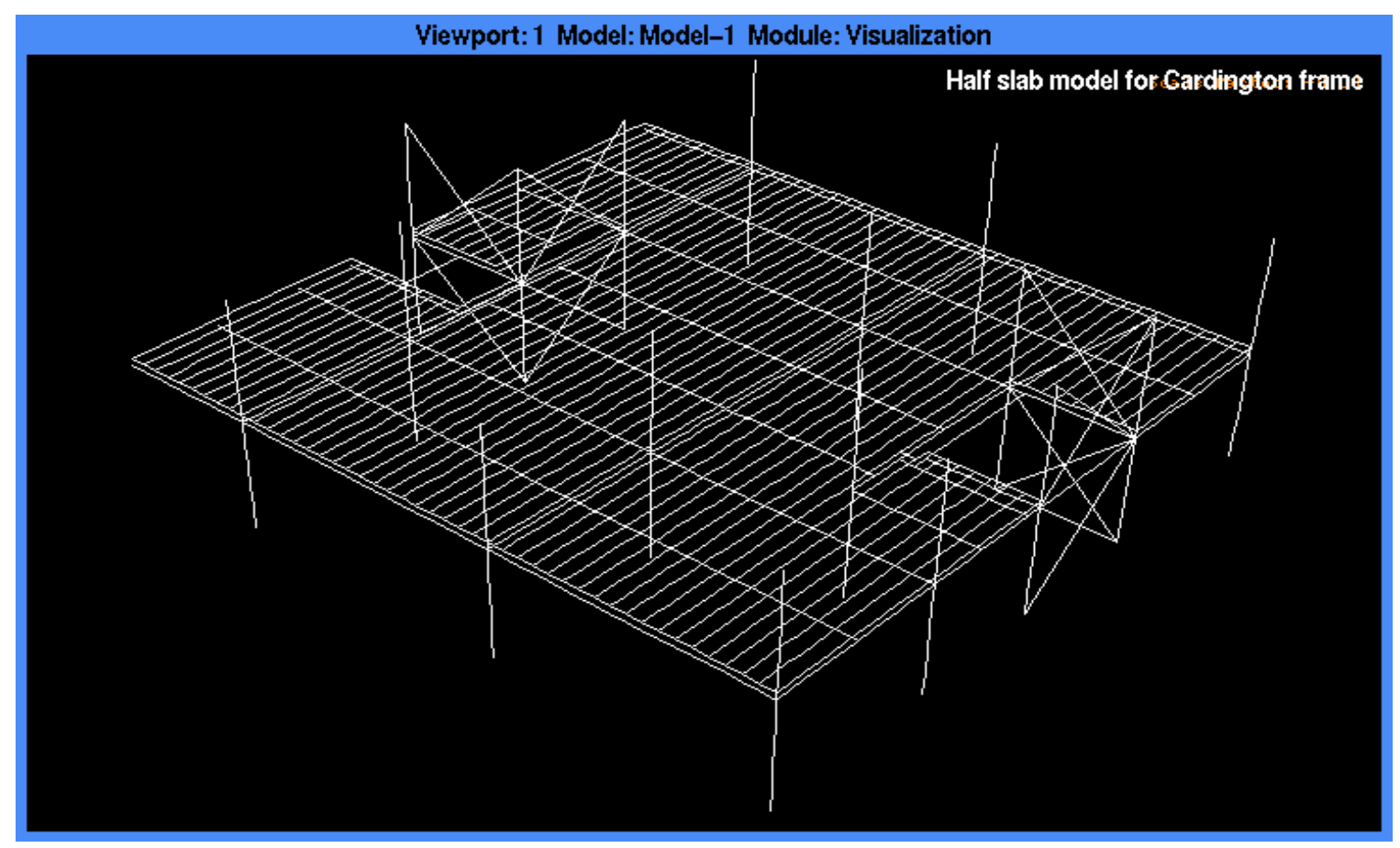

Figure 3 - Grillage model for concrete slab

The slab behaviour is modelled by a grillage type idealization using beam elements to represent the slab behaviour in both the longitudinal and transverse directions. In the longitudinal direction $(\mathrm{X})$, the slab element has a rectangular section with $70 \mathrm{~mm}$ depth and an effective width equal to $2250 \mathrm{~mm}$, calculated according to Eurocode 4 [5] for a simply supported beam case. In the transverse direction (Y), slab elements have a trapezoidal shape and the geometry of the concrete section in this direction is shown in Figure 2. Table 2 gives the dimensions of the used composite sections in both directions.

\section{Material behaviour}

For concrete exposed to high temperature, the relationship between stress and strain changes considerably. At increased temperature, the material properties degrade and its capaci ty to deform increases which is measured by the reduction of Young's modulus. In the finite element model, the relation between the stress and the strain under high -temperature is defined according to Eurocode 2 [3] as shown in Figure 4. The initial elastic behaviour is followed by a plastic-hardening curve up to the ultimate stress, after which, a decaying zone represents the post-crushing behaviour of concrete. This relationship has the advantage of allowing the definition of a stress level for large plastic deformations, usually reached during fire conditions. It may be noted that no tension stress is considered in the model for the 
concrete at both ambient and elevated temperature s; however the tensile resistance of the reinforcement and the steel deck is considered according to Eurocode 3 [4].

\section{Properties of concrete at high temperature}

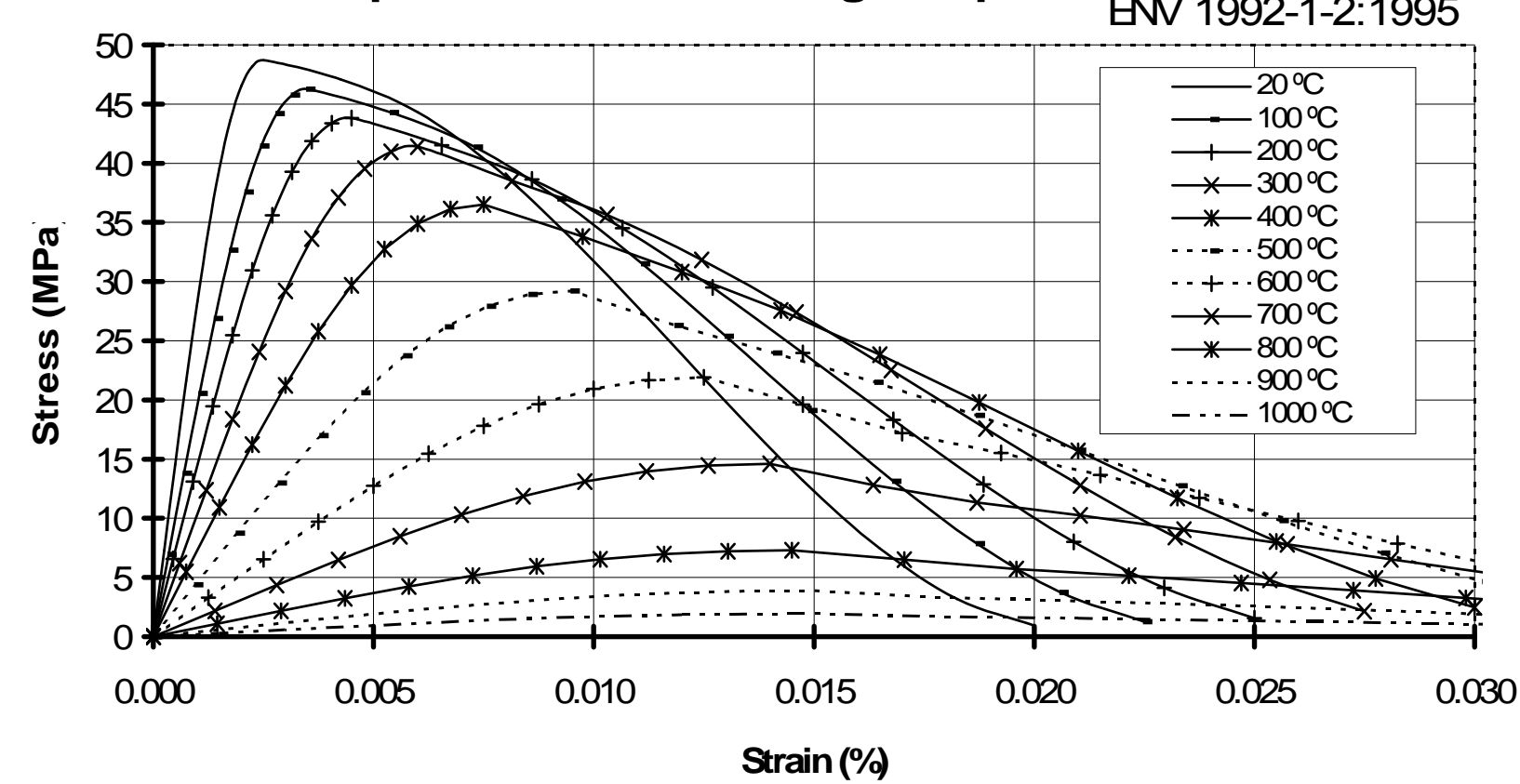

Figure 4 - Concrete stress-strain relationship at high temperature

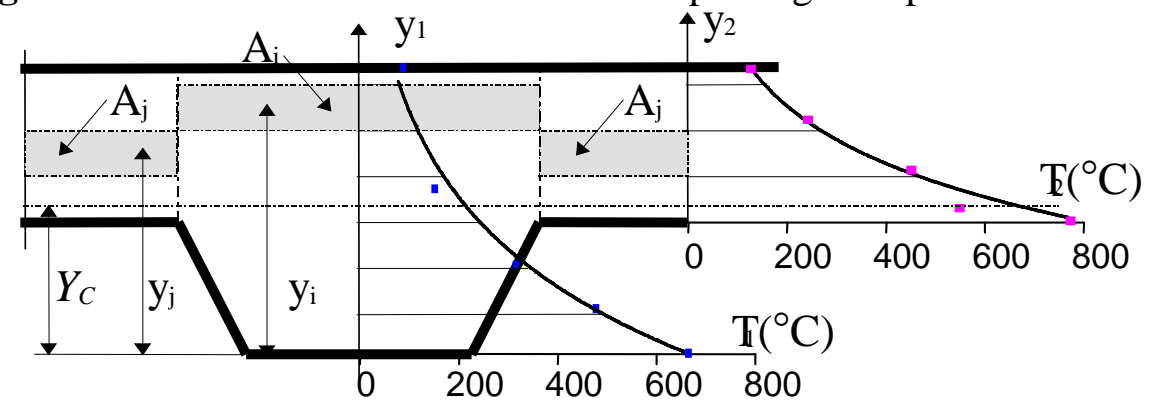

Figure 5 - Vertical Distribution of Temperature through the concrete slab thickness

\section{Slab modelling}

In a reinforced concrete slab, complex behaviour has to be modelled. The difference in behaviour of RC slab in tension and compression, the orthotropic behaviour of concrete due to the reinforcing mesh and the decking steel as well as the development of membrane action need to be considered in order to provide a realistic representation of the slab behaviour. In the developed model, the RC slab is divided into layers for both of the thin part and the ribs. Each concrete element is based on the global behaviour of the concrete sectio $n$, with the above factors taken into consideration. The slab is modelled by two sets of beam elements running parallel and perpendicular to the secondary beams. In each direction, the beam elements have a pre-defined force-strain and moment-curvature relationships. These 
relationships are calculated based on the geometry and the material properties of the cross section in each direction and taking into account the variable temperature over the same section as well as the corresponding material properties. The axial force-strain relationship at temperature $(t)$ takes the following form:

$$
F_{C}^{t}=\sum^{n p 1} \sigma_{C i}^{t}\left(\varepsilon_{m}\right) A_{i}+\sum^{n p 2} \sigma_{C j}^{t}\left(\varepsilon_{m}\right) A_{j}+\sigma_{S D}^{t}\left(\varepsilon_{m}\right) A_{S D}+\sigma_{S M}^{t}\left(\varepsilon_{m}\right) A_{S M}
$$

and, the riroment-curvature relationship at temperature $(t)$ :

$$
M^{t}=\sum_{i=1}^{n p 1} \sigma_{C i}^{t} A_{i}\left(y_{i}-Y_{C}\right)+\sum_{j=1}^{n p 2} \sigma_{C j}^{t} A_{j}\left(y_{j}-Y_{C}\right)+\sigma_{S D}^{t} A_{S D}\left(Y_{S D}-Y_{C}\right)+\sigma_{S M}^{t} A_{S M}\left(Y_{S M}-Y_{C}\right)^{\text {Eq. } 2}
$$

with $\sigma_{C j}$ is the stress in concrete at layer $j$ which depends on the mechanical strain $\varepsilon_{m}$ at this level,

$\sigma_{S D}$ is the stress of steel deck, $\sigma_{S M}$ is the stress of secondary steel mesh,

$\mathrm{A}_{\mathrm{i}}, \mathrm{A}_{\mathrm{j}}, \mathrm{A}_{\mathrm{SD}}$ and $\mathrm{A}_{\mathrm{SM}}$ are the areas of concrete layer in thin part, the area of concrete layer in the rib part, the area of steel deck and the area of steel mesh respectively,

$Y_{i}, Y_{j}$ and $Y_{C}$ are respectively the distance of thin layer, rib layer and centroid of the section from the lower deck.

The behaviour of the RC slab in the longitudinal direction (direction of the secondary joists axis) produces a bilinear moment/curvature and force/strain relationships which are uncoupled as shown in Figure $6 \&$ Figure 7. The yield points for the force relationship in each sense are given by the section's plastic resistance for normal force (with different values for tension and compression). The yield points for the bending relationship are given by the section's plastic resistance for bending (with different values for sagging and hogging moments). The post-yield behaviour is modelled by a linear relationship (moment/curvature and force/strain), decreasing from the yield point to the ultimate section resistance based on the steel reaching the limiting strain for yield strength.

The behaviour of the slab in the transverse direction (direction of the primary joist $\mathrm{s}$ axis) is also modelled by beam elements. The transverse bending and transverse membrane action of the slab produce the uncoupled bilinear moment/curvature and force/strai $\mathrm{n}$ relationships shown in Figure $8 \&$ Figure 9. All over the slab, the beam ribs have a very high bending stiffness about the vertical axis (i.e. relating to bending deformations in the hor izontal plane) this is modelled by increasing their bending stiffness to 100 times the bending stiffness of an individual rib. To overcome convergence problem $\mathrm{s}$ in the numerical solution, the slab tension and hogging moment including hardening beyond the first yield point. The beam element used in modelling the slab is a 3D beam element with linear elastic behaviour for torsion . 
Behaviour of the slab section in the longitudinal direction

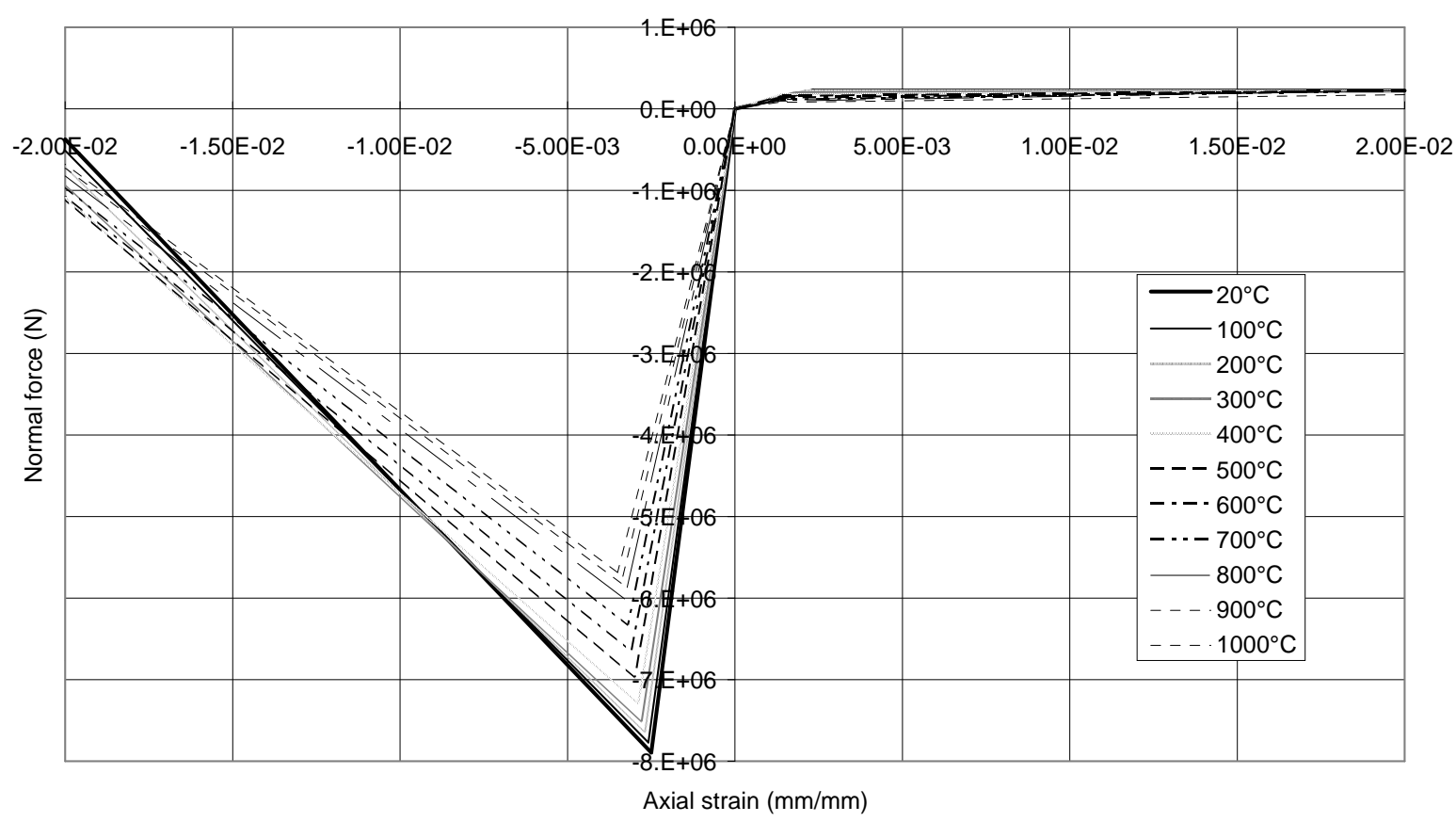

Figure 6 - Axial Force - Axial Strain relationship at high temperature in the longitudinal direction of tested concrete composite slab

Behaviour of the slab section in the longitudinal direction

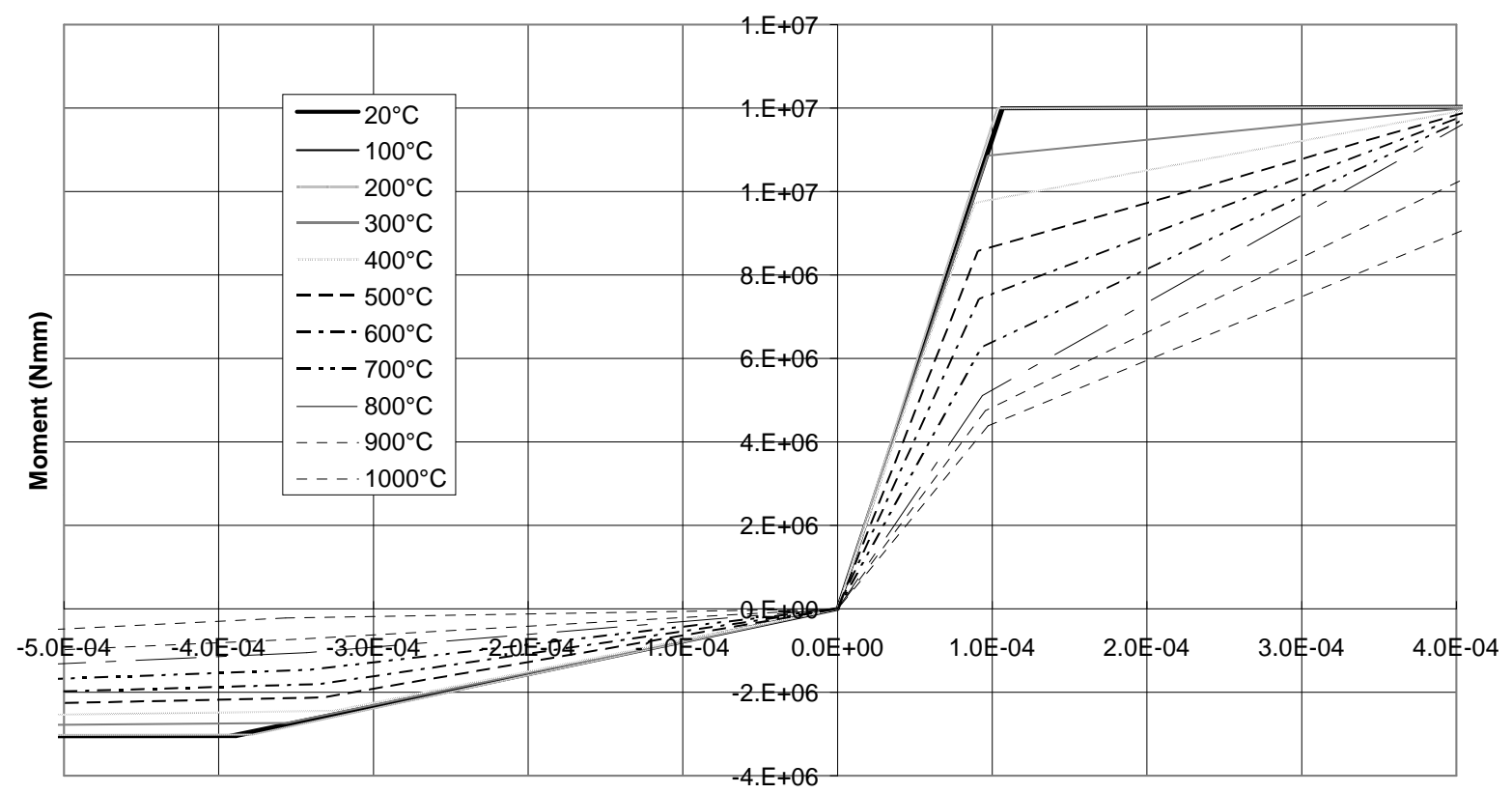

Curvature $(1 / \mathrm{mm})$

Figure 7 - Moment-Curvature relationship at high temperature in the longitudinal direction of tested concrete composite slab 
Behaviour of the slab section in the lateral direction

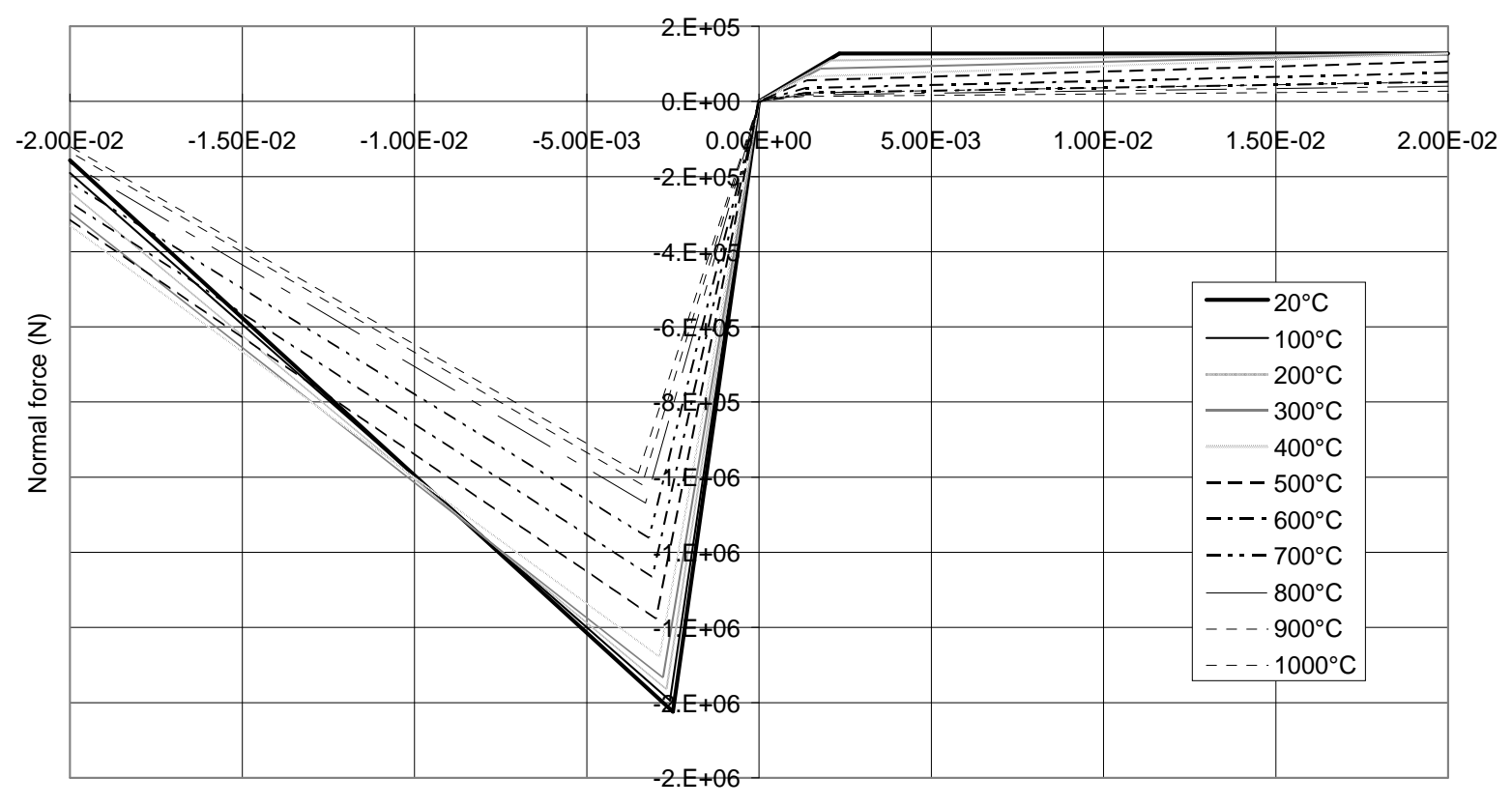

Axial strain $(\mathrm{mm} / \mathrm{mm})$

Figure 8 - Axial Force- Axial Strain relationship at high temperature in the lateral direction of tested concrete composite slab

Behaviour of the slab section in the lateral direction

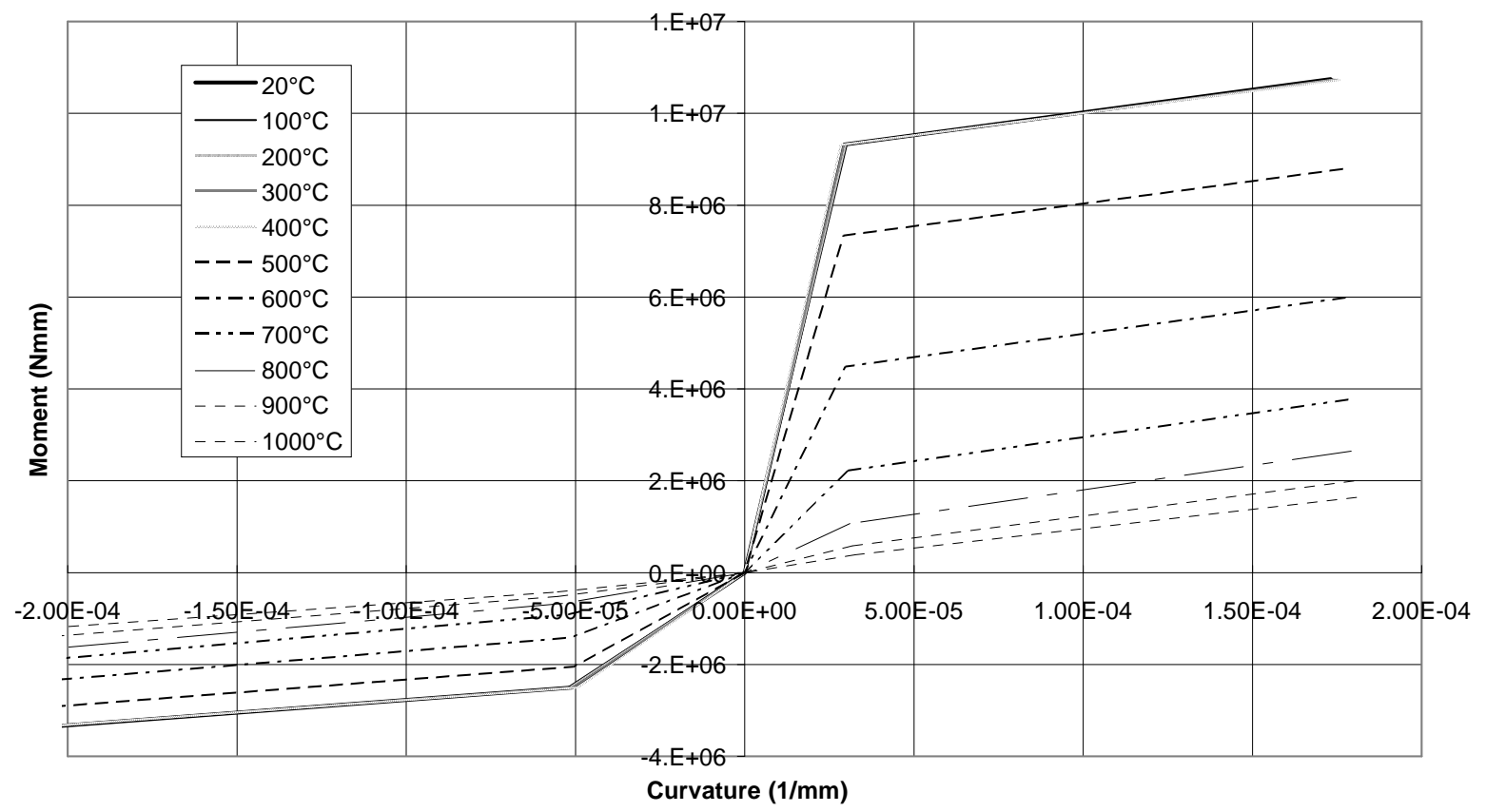

Figure 9 - Moment-Curvature relationship at high temperature in the lateral direction of tested concrete composite slab 


\section{$\underline{\text { Distributed load }}$}

The self-weight of the composite steel structure and the live load applied during the test are combined to give an imposed floor load of $5.48 \mathrm{kN} / \mathrm{m}^{2}$. In the developed numerical model, a distributed load of $5.48 \mathrm{kN} / \mathrm{m}^{2}$ is applied to the slab by means of the uniformly distributed loads on the ribs of $1.644 \mathrm{kN} / \mathrm{m}$ '. This is maintained at constant value throughout the thermal loading process. Non linear geometric and material effects were included based on the large deformation theory using the Newton-Raphson method [1].

\section{Thermal load}

The effect of fire on the concrete composite structure is modelled by increasing the temperature linearly over 2 steps, from ambient temperature to the maximum temperature reached for each member separately. The thermal effect on the structure was modelled by considering both, the expansion of each element as well as the thermal gradient across its section. These two factors are applied to the RC slab as well as the steel joists. Thermal loading is applied only to the compartment heated zone and outside it according to the test measurements. It is applied by defining the final temperature over each steel joist and assuming a linear variation from the initial temperature $\left(0^{\circ} \mathrm{C}\right)$ to the final temperature. Each joist has a centroid constant temperature along its total length and has a vertical variation in temperature across its section. The vertical variations in temperature are included as a direct input following the test measurements. Temperature gradients are modelle $d$ in both the slab and the joists. For the beam adopted finite elements mesh, the temperatures are defined at five points across the joists section (the centroid and 2 points in each flange). The extreme fibre temperature of the lower flange of the second ary joist in each test is used as the Reference temperature (RLFT). It is the average of the input temperature values for the 2 points in the lower flange.

For the composite slab, only the zone within the compartment is heated. The parts of the slab which lie outside the compartment zone are treated as remaining at ambient temperature at all times. The heating effects for the slab (membrane and gradient values) are applied both to the longitudinal and transverse slab models separately. The temperatures of all points in the slab which lie within the compartment are treated as equal at a given height within the slab. Each rib has a constant temperature over its heated length and is considered to be at ambient temperature outside the furnace. It may be noted h ere that the temperature applied to the slab is the mean temperature acting on its geometric centre and the gradient across its thickness is the mean gradient deduced from the temperature distribution calculated separately from the longitudinal and the transverse directions. In the model, the temperature varies from one beam to the other according to the measured temperatures.

\section{Validation of developed slab model}

\section{Fire Test 1}

The above developed slab model is implemented here into the finite element simulati on for fire test 1 . In this test, the heated zone was symmetric, thus only half of the zone was 
modelled. In the transverse direction (y), the model extended $4.5 \mathrm{~m}$ on either side of the heated beam to include the adjacent unheated secondary beams and half the span of the next slab. Thus, a total of four secondary steel joists and two primary joists were considered. Each of them is treated as a steel thin walled I-section rigidly connected to the composite slab. The beam to column connections as well as beam to beam connections were modelled each with rigid links connecting the displacements and rotations of the beam nodes to those of the column or other beam. For the boundary conditions, at the ends of the ribs the translations in the $\mathrm{x} \& \mathrm{y}$ directions and the rotations about the $\mathrm{x} \& \mathrm{z}$ axes were all restrained (symmetry). All along the primary beams, the $\mathrm{x}$-translation and the rotations about the $\mathrm{y} \& \mathrm{z}$ axes were restrained to model the continuity of the slab. At the bottom of the column, all displacements and rotations were restrained, whilst at its top only vertical displacement was permitted.

\section{Temperature regime}

The fire was modelled by heating up the RC slab and the steel joists progressively using the measured temperatures of the test until the maximum temp eratures were attained. The temperatures measured at the centroid of the slab in the transverse and longitudinal directions are plotted against the time after the start of the fire as shown in Figure 10. Although the temperature of the different parts of the structure does not increase proportionally with each other, an attempt was made to achieve a model which would not depend so much on the detail of the rate of heating of each part. It was therefore assumed that all temperature s increased linearly from ambient to the maximum value for that member.

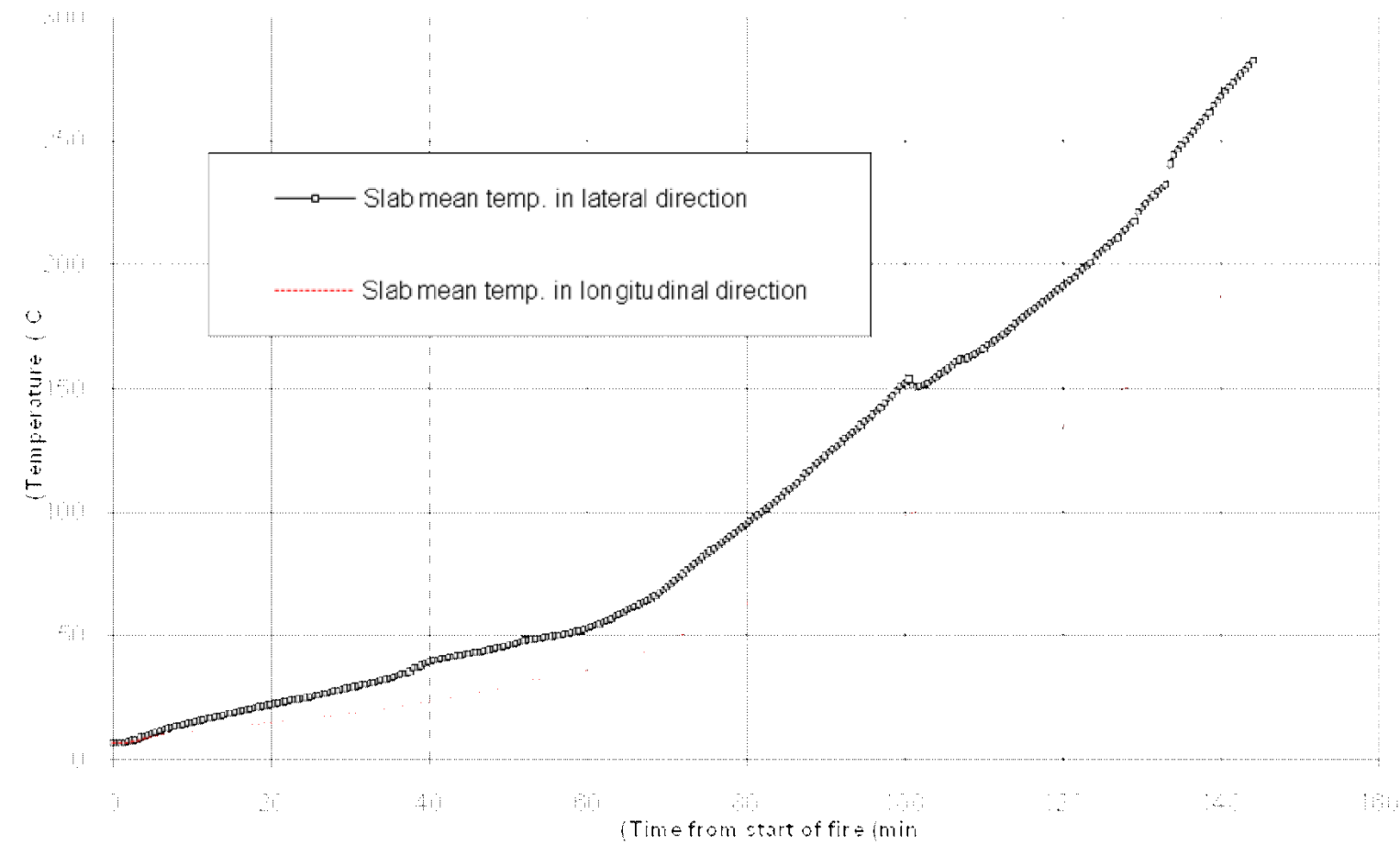

Figure 10: Temperature-Time Relationship during Fire Test 1

\section{Deflection of tested beam}


Deflection measurements were taken along the heated steel joist. The maximum deflection observed for joist was at mid-span $(\mathrm{x} / \mathrm{l}=0.5)$ and minimum deflection near the column $(\mathrm{x} / \mathrm{l}=0.04)$. Here the numerical predictions are compared with the experimental results for the two locations. Figure 11 shows the relation between the deflection of the beam at the two locations and the reference temperature of the lower flange of the heated joist at mid -span. The negative sign for the deflection indicates downward movement and a good overall agreement can be observed between the two curves during the full duration of the fire.

\section{Horizontal displacement of columns}

The relative displacement of columns on either side of the tested secondary joist was measured in the test, and due to the symmetry assumed in the model, this relative displacement was divided by two to give a measure of the actual horizontal displacement of one column. This value is compared with the numerical prediction as shown in Figure 12 where qualitative and reasonable quantitative agreements between the model and test are obtained.

Test 1: Joist deflection under increasing temperature

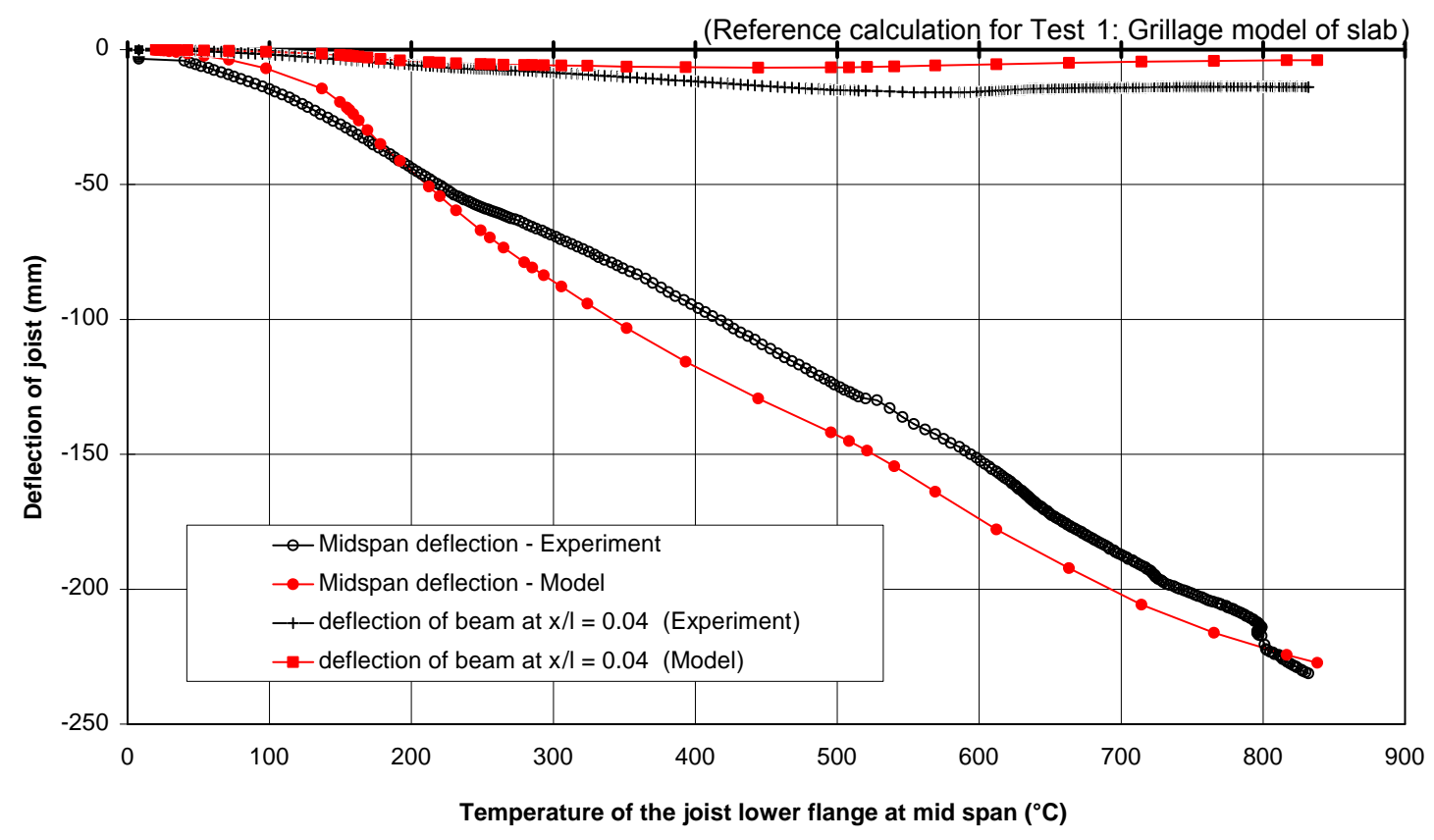

Figure 11 Comparison of Model and Experimental deflection results for Fire Test 1 


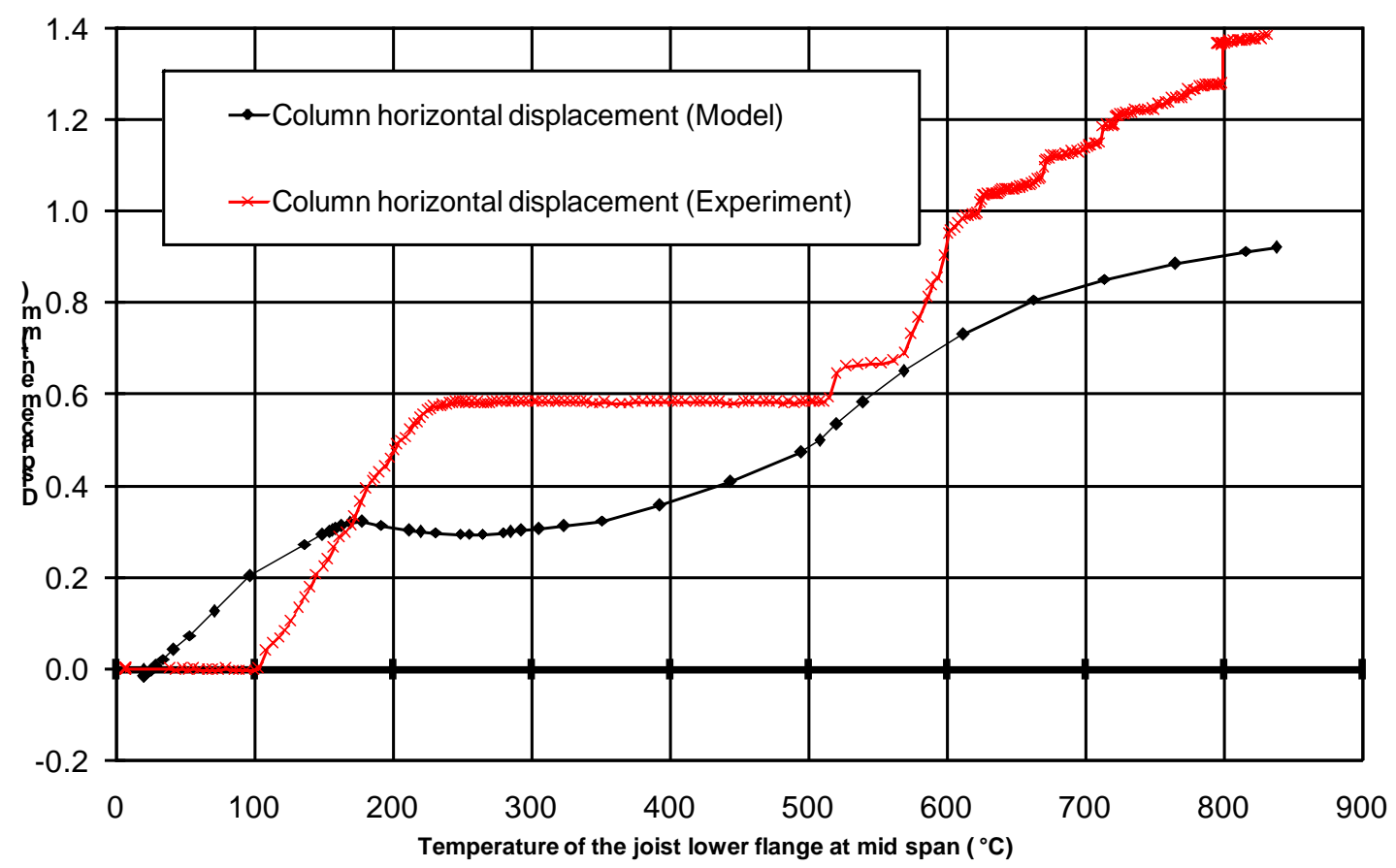

Figure 12 - Horizontal displacement at the floor level

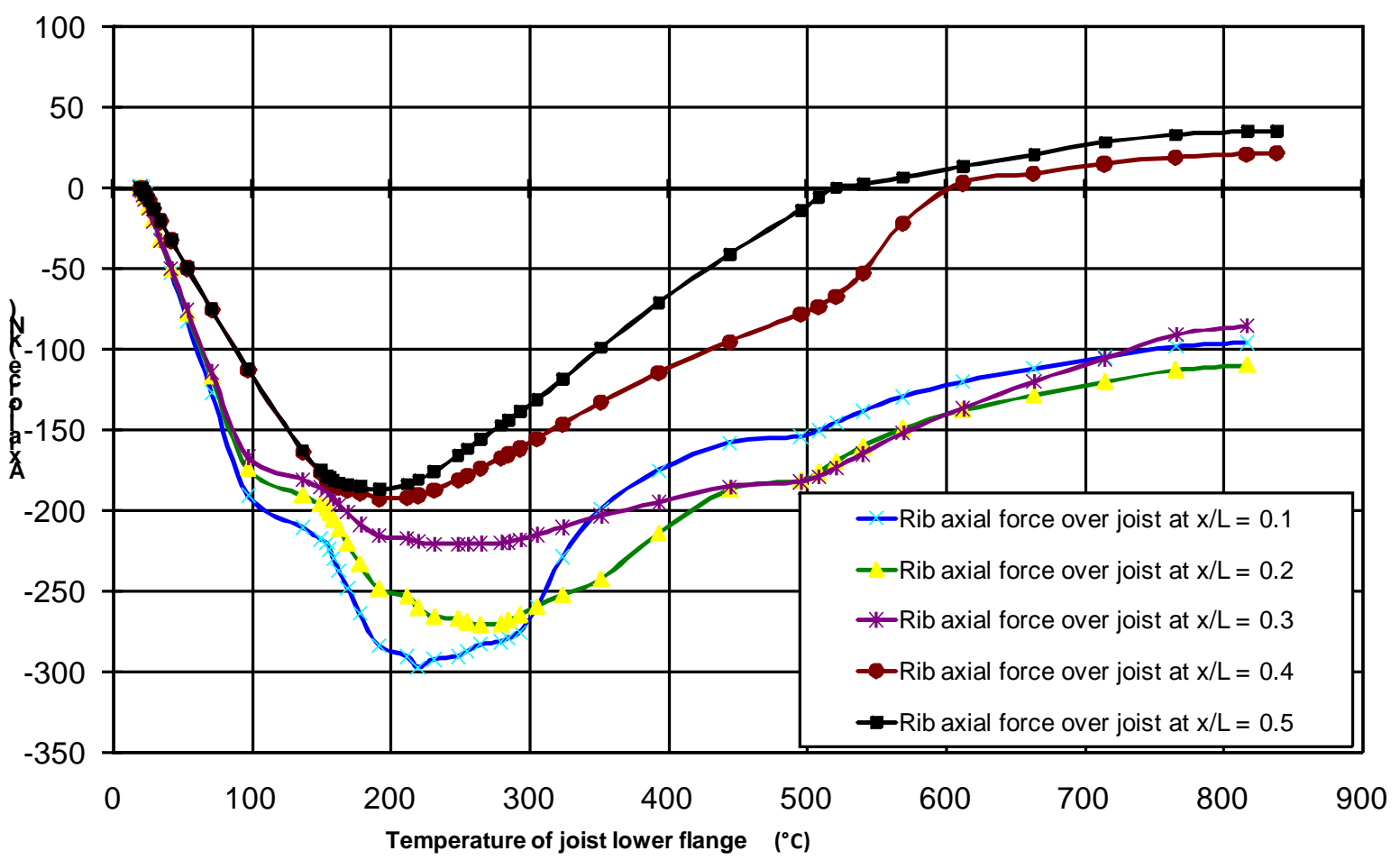

Figure 13 - Membrane forces in the transverse direction in the RC slab (ribs) 


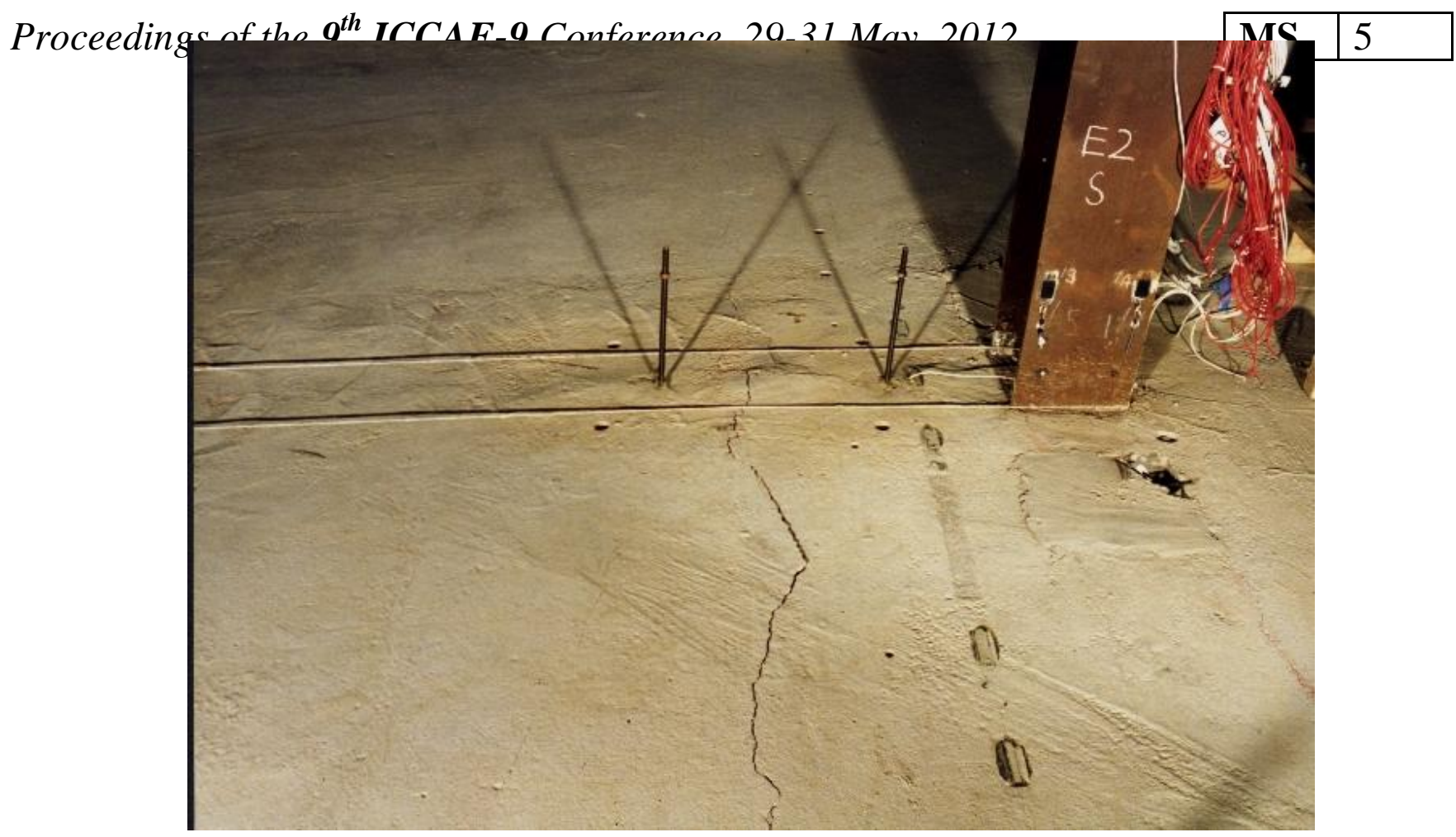

\section{Horizontal forces in slab}

The axial forces developing in the ribs of the slab in the transverse direction are shown in Figure 13. At ambient temperature, these membrane forces are tiny. Between $20^{\circ} \mathrm{C}$ and $200^{\circ} \mathrm{C}$, the ribs develop compressive forces as their expansion is restrained by the cold surrounding slab. The magnitude of the compressive force developed in each rib depends upon its location because deflections permit the expansion to be accommodated without compressive force development Rotter et al.[11]. Thus the ribs near the primary beam develop higher compressions because they deflect less and those near mid -span develop lower compressions because they deflect more. From $200^{\circ} \mathrm{C}$ onwards, the axial compression in every rib reduces, and the ribs near mid-span $(\mathrm{x} / \mathrm{L}=0.4 \& \mathrm{x} / \mathrm{L}=0.5)$ develop tension at temperatures above $500^{\circ} \mathrm{C}$.

The tensile membrane action is mobilized by the large displacement effects as the relative magnitudes of joist deflections and rib thermal expansion compete under the requirement $\mathrm{s}$ of compatibility. It should be noted that quite small tensile forces can carry substantial loads because the deflections have already become large, and these tensile forces in slab lie far below its tensile capacity at the relevant elevated temperatures . This tensile membrane action reduces the applied moment on the slabs and allows it to distribute by bridging over the heated zone preventing any collapse of floor that may occur even after the joist ceases of carrying the transverse loads.

Figure 14 shows the cracks developed at the top surface of the heated slab after the fire. It demonstrated the development of the tensile force detected by the numerical model simulation.

\section{Fire Test 3}


The described slab model de veloped above is implemented here into the finite element model to simulate the fire test 3 . In the direction of the secondary beams (longitudinal), the model starts from the corner of the structure, covers the heated compartment and extends to the end of the span beyond the compartment to include the membrane forces expected to develop during the fire. In the transverse direction (direction parallel to the slab ribs), the model starts from the edge of the building, cover s the heated compartment and extends to the centreline of the building for the same reason. In the model, each structural steel member is idealized by an appropriate beam element.

\section{Temperature regime}

Time variation of temperature inside the fire compartment follows the curves show in figure 12. The number of measuring points was very few; only 4 points over the $80 \mathrm{~m} 2$. The heating was divided into 2 linear steps. First from $0^{\circ} \mathrm{C}$ to $200^{\circ} \mathrm{C}$ and the second step up to $400^{\circ} \mathrm{C}$.

Structur al Element Temper atures in Test 3

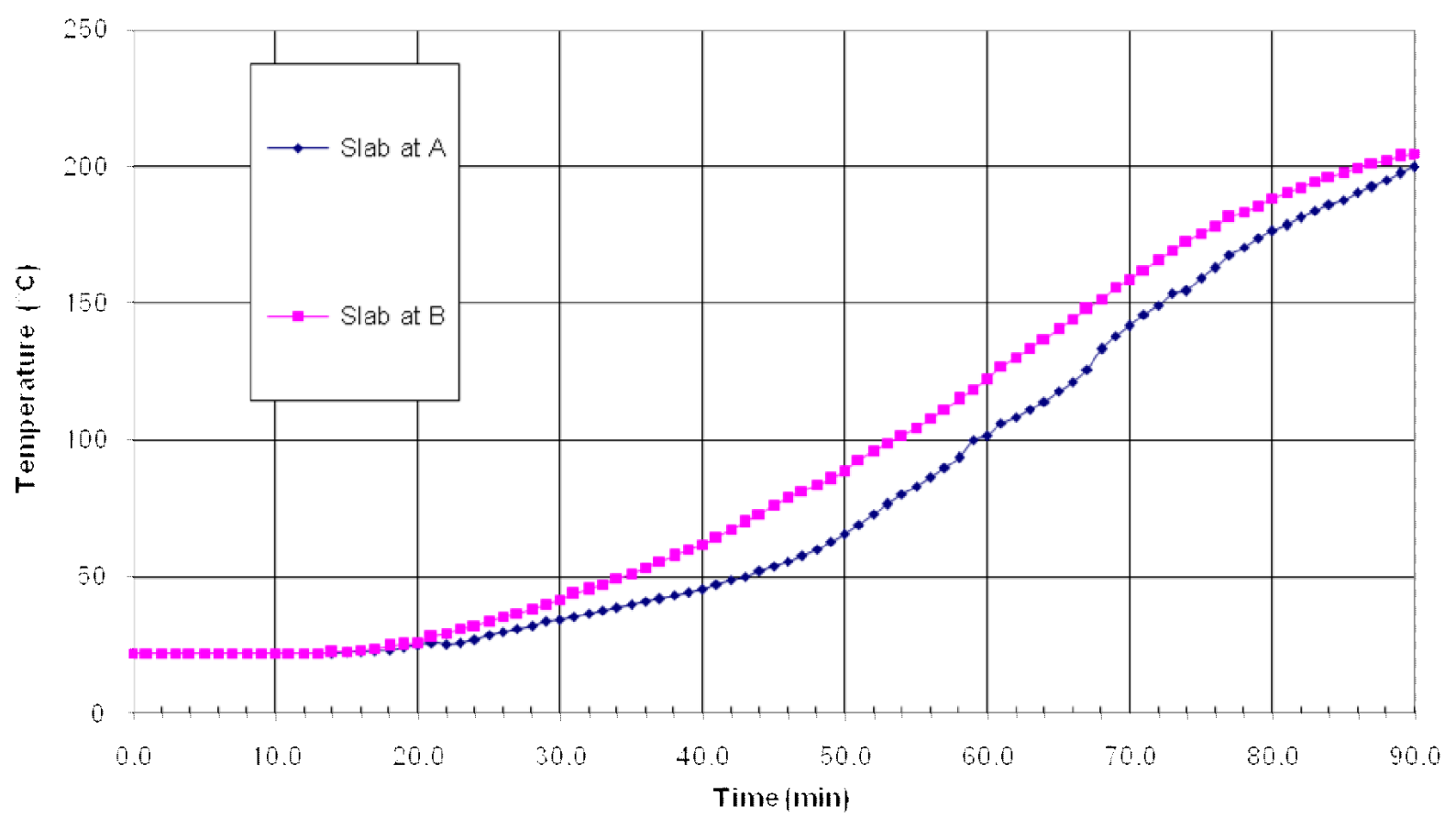

Figure 15 - Slab Temperatures during Fire Test3

\section{Deflection of beams}

Many measurements were taken over the heated joists. The maximum deflection observed for each joist was at mid-span. Similar deformation is predicted by the finite element simulation and the numerical prediction of the maximum deflection is compared with the experimental results. First comparison is for the heated primary beam. The first measurement point is located on the bottom flange of the beam at mid-span. Figure 16 shows the relation between 
the deflection of the beam at this point and the R eference Lower Flange Temperature (RLFT) of the hottest secondary joist at mid-span. The negative sign for the deflection indicates a vertical displacement downward. In both the finite element analysis and the experiment, the deflection increases with temperature and the experimental measurements show a non -linear relationship with three major patterns. First from 0 to $600^{\circ} \mathrm{C}$ (RLFT) a non linear increase of deflection against temperature occurs, then from $600^{\circ} \mathrm{C}$ to the $900^{\circ} \mathrm{C}$ the overall linear pattern is characterized by a flatter slope, then during the final stage from $900^{\circ} \mathrm{C}$ to $1000^{\circ} \mathrm{C}$ the deflection increases rapidly against the temperature. In this last phase the rapid increase in deflection is due to a rapid increase in the slab temperature, which combined with the steel joists temperature produces the overall thermal regime applied to the composite slab.

In the finite element analysis two main patterns can be distinguished, firs $t$ from 0 to $690^{\circ} \mathrm{C}$ where the deflection increases with nearly a linear relationship, followed by the second phase up to $1000^{\circ} \mathrm{C}$ in which the relation becomes non-linear with a rapid increase of the deflections against the time. The deflection predicted by the numerical model reaches the same final value of $100 \mathrm{~mm}$ at $1000^{\circ} \mathrm{C}$, with close values all the way during the fire. The maximum difference between the model and the test is approximately $10 \mathrm{~mm}$ and recorded near $700^{\circ} \mathrm{C}$. The difference between the model and the test can be attributed to the approximated temperatures applied over mainly the slab. It is to be noted here that the measurement of temperature over the slab was insufficient to give a complete spatial distribution.

Test 3 Joist deflection under increasing temperature

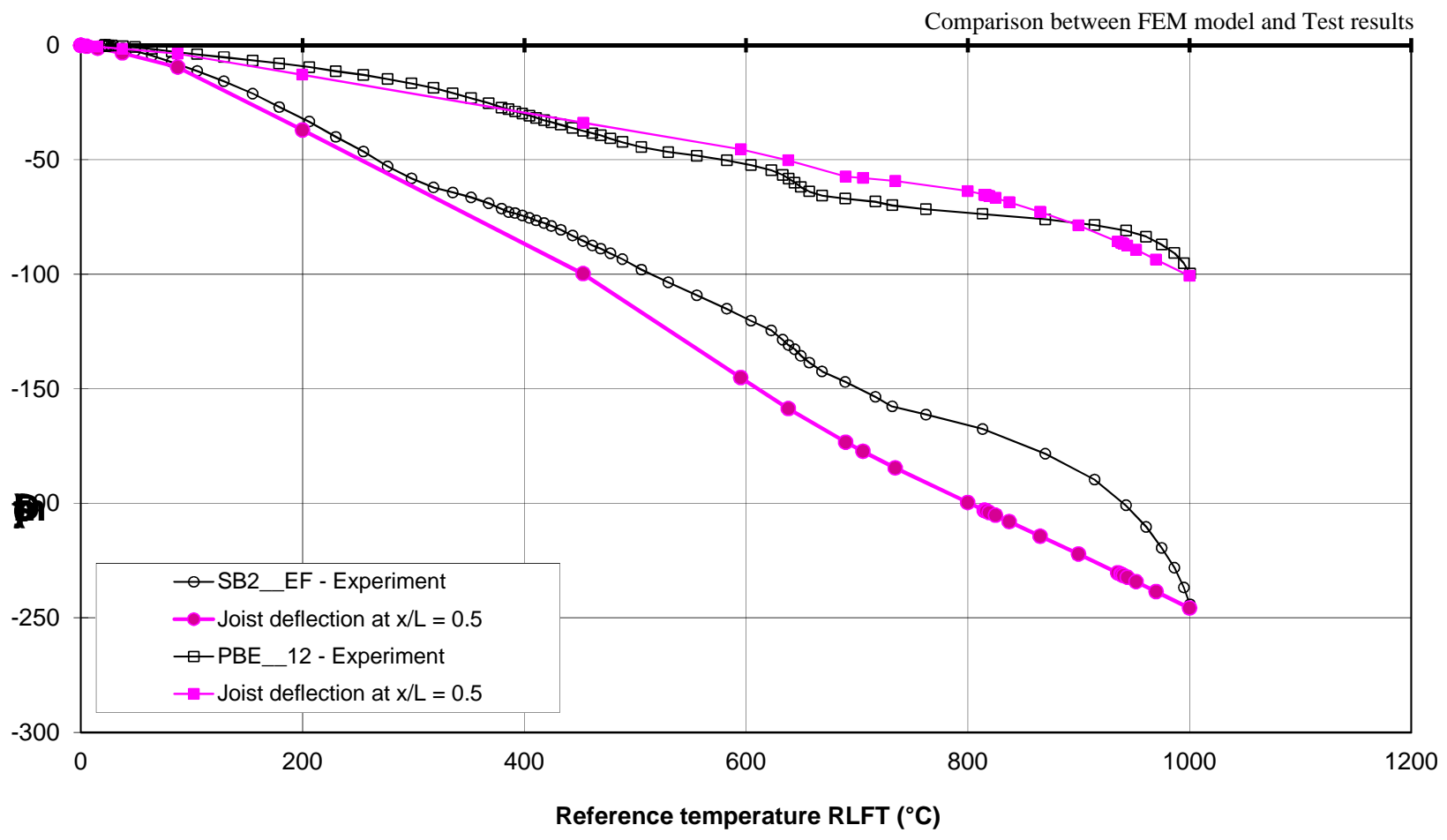

Figure 16 - Comparison of Model and Experimental results for Fire Test 3 
To ensure that deflected shape of the beam is coherent between the model and the experiment, a second comparison is carried for the other heated secondary joist. This joist was connected to a column at each end and the maximum deflection was obtained at mid -span. In Figure 16, it can be seen that the behaviour is nearly all through the heating regime from $0^{\circ} \mathrm{C}$ to $1000^{\circ} \mathrm{C}$. The first part of the relationsh ip is very similar to the pattern observed in Test 1 for a similar restrained secondary beam Sanad [12]. The second part of the behaviour is identical with the last pattern observed for the primary beam and is mainly due to the temperature regime applied to the structure at the end of the fire. The numerical predications are in good agreement with the measurement for most of the fire time and the difference observed in the 2 curves at the end of fire is again related to the temperature regime applied to the structure.

\section{Horizontal displacement of columns}

A comparison was made for the displacement of the columns above the floor, where transducers were installed to measure the horizontal displacements of columns. For column E1 connected to the heated primary beam, the measured displacements are compared with the numerical predictions in Figure 17. The horizontal displacement is plotted against the reference temperature of the joist lower flange at mid-span; the positive sign indicates a horizontal displacement towards outside of the building on the axis of the prim ary beam. 


\section{Test 3: Column displacement under increasing temperature}

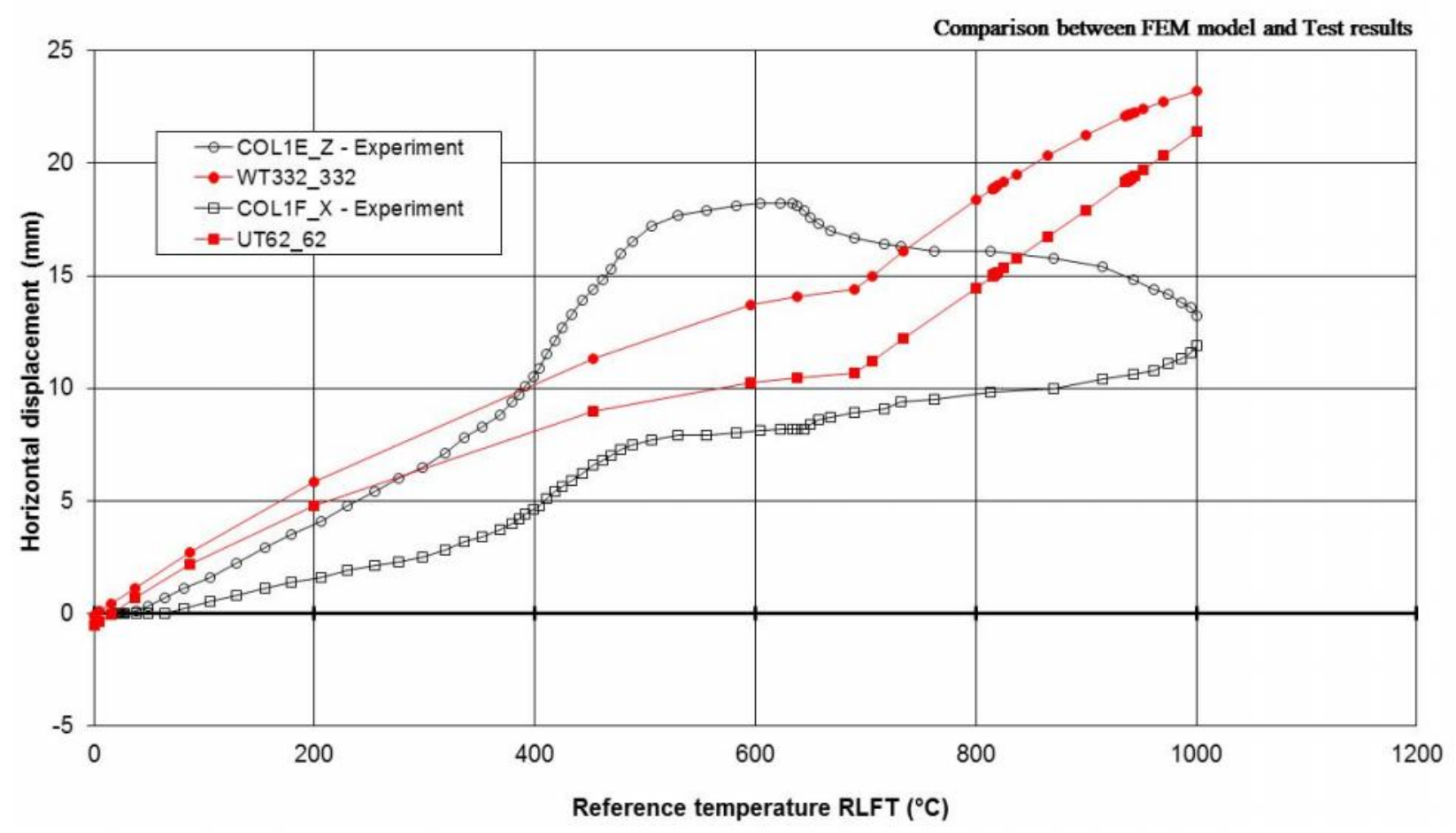

Figure 17 - Horizontal displacement of column $\mathrm{E} 1$ in y direction and F1 in $\mathrm{x}$ direction

The comparison here shows that the order of magnitude of the displacement obtained from the numerical model is comparable with the test results. The model predicts $23 \mathrm{~mm}$ of column displacement outside the building against nearly $13 \mathrm{~mm}$ from the test. In the test, the horizontal displacement reaches a maximum value between $500^{\circ} \mathrm{C}$ and $600^{\circ} \mathrm{C}$ then it reduces nearly linearly to $13 \mathrm{~mm}$ till the end of the heating regime. In the numerical model the displacement is steady toward the outside of the building from the start to the end of the fire with a variation at $620^{\circ} \mathrm{C}$ corresponding to the change from step 1 to step 2 in the modelled heating temperature and the difference between the shape of the curves in the experiment and the numerical model can be related to the simplified heating regime adopted in the model. 
Slab axial force at different locations

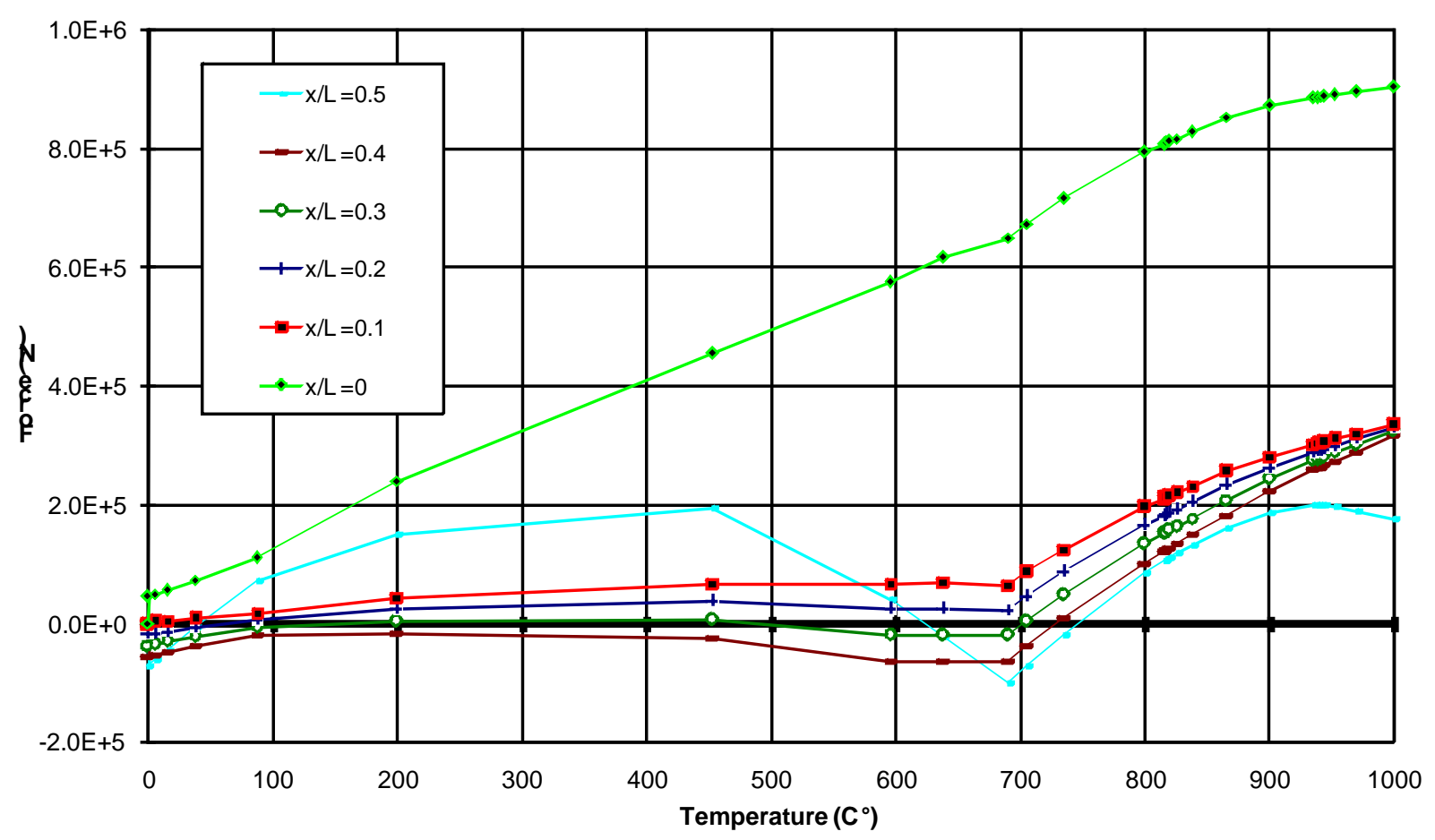

Figure 18 - Slab tensile force

The second comparison is carried for the horizontal displacement of corner column F1 in the direction of the secondary beam (direction $\mathrm{x}$ ). The shapes of the curves in the model and the test are similar to each other. The model predicts an increase in the horizontal displacement from 0 to $400^{\circ} \mathrm{C}$ then a plateau to $690^{\circ} \mathrm{C}$ followed by a linear increase to the end of the test . The magnitude of the horizontal displacement is $12 \mathrm{~mm}$ at end of fire in test against 22 in the model. The direction of the displacement is directed again outside the bui lding on the axis of the edge protected secondary beam indicating that the floor is expanding in the $\mathrm{x}$ and $\mathrm{z}$ directions as obtained from the previous comparison. This important aspect of the behaviour of the slab is predicted in the numerical model and agr ees with the test measurements.

\section{Horizontal forces in slab}

Figure 18 shows the internal axial force developed in the heated slab during the fire. The results are presented for 5 transverse ribs crossing the secondary beams at different locations . The first rib $(\mathrm{x} / \mathrm{L}=0)$ is just above the edge primary beam. It behaves compositely with the primary beam to carry the imposed load. Large tensile force is developed in this rib and increases with temperature due to the difference in heating regime between the concr ete slab and the steel joists. The temperature and thermal expansion of the edge beam is larger than the slab connected to it, which creates compression in the joist and tension in the slab. The other curves in the figure show the development of large tens ile forces in all ribs from $700^{\circ} \mathrm{C}$ 
to $1000^{\circ} \mathrm{C}$. At this temperature, the secondary steel joists have lost most of their strength due to material degradation. The transverse ribs develop large tension to bridge over the damaged steel joists and redistribute the imposed load by tensile membrane action to the non damaged joists outside the fire compartment.

In short, the comparisons between the finite element predictions and the test measurements show an overall good agreement for different quantities of deflecti ons and horizontal displacements over the total time of the fire. The different simplifications used in the model, can be applied with reasonable confidence to predict with acceptable accuracy the global behaviour of the structure under fire conditions.

\section{CONCLUSIONS}

This paper presents a simplified formulation for RC slab to model composite floor behaviour under fire conditions. The orthotropic slab is represented by a grillage model as its stiffness in the direction of the decking troughs or ribs (transvers e) is significantly higher than in the longitudinal direction. The slab geometry is idealized using a beam member in the transverse direction for the T-beam corresponding to each rib and another beam member above each joist for the composite action of the slab with the joists. This m odel leads to simple interpretations of composite beam behaviour which can be used to give a clear understanding of the phenomena occurring during fire. The slab grillage model was implemented in a large finite element model to simulate two full scale fire tests. The finite element results were in good agreement with the test measurements. The analysis of the results at high temperature showed the patterns of the development of forces within the slab during a fire. The results confirm that it is the thermal effects of restrained expansion and bowing due to vertical thermal gradients that govern the response of the structure for the whole temperature range of the fire. The internal forces developed in the structure far exceed those caused by the imposed loads. The stability of the structure at high temperature is insured by the development of tensile membrane forces within the slabs that bridge over the heated compartment and develop alternative load carrying mechanisms to distribute the newly imposed load to the surrounding unaffected elements.

\section{References}

1. ABAQUS (1994), "ABAQUS theory manual and user's manual, version 5.4", Hibbit, Karlsson and Sorensen Inc., Pawtucket, Rhode Island, USA

2. Bravery P.N.R., "Cardington large building test facility, Construction details for the first building", internal report British Steel plc., UK, 1995. 
3. Eurocode 2, " Design of concrete structures - Part1-2 : General rules - Structural fire design", ENV 1992-1-2, 1995.

4. Eurocode 3, "Design of steel structures - Part1-2 : Fire resistance", ENV1993-1-2, 1995.

5. Eurocode 4, "Design of composite steel and concrete structures - Part1-1 : General rules and rules for buildings", ENV 1994-1-1, 1994.

6. Gillie M. " Development of generalized stress strain relationship for the concrete slab in shell models", PIT Project Research Report: SS1, University of Edinburgh, 1999.

7. Gillie M., Usmani A., Rotter M., " Bending and membrane action in concrete slabs", Fire and Material Journal, volume 28, issue2-4, March 2004.

8. Khoury G.A., Grainger B.N. and S ullivan P.J.E., "Strain of Concrete during fire heating to $600^{\circ} \mathrm{C}$ under load", Magazine of Concrete Research Vol. 37, 195-215, 1985.

9. Kirby B.R., "Behaviour of a multi-story steel framed building subject to natural fires: Test3-restrained beam, deflection measurements", Document ref; S423/1/Part D1, British Steel plc., 1995.

10. O’Connor D.J., McAllister B., Munro J. and Bennett H.R., "Determination of the fire endurance of model concrete slabs using a plastic analysis methodology", The Structural Engineer, Volume 73, No. 19, October 1995.

11. Rotter, J.M., Sanad, A.M., Usmani, A.S. and Gillie, M., "Structural performance of redundant structures under local fires", Proc., Interflam '99, 8th International Fire Science and Engineering Conference, Edinburgh, 29 June - 1 July, Vol. 2, pp 1069 1080, 1999.

12. Sanad, A.M., "Behaviour of Indeterminate beam under fire condition", Helwan Eng. Journal, Vol. 33, 2012.

13. Sanad A.M. "British Steel Fire Test1: Reference ABAQUS model using grillage representation for slab" Research report R99-MD1, University of Edinburgh, Department of Civil and Environmental Engineering, 1999.

14. Sanad A.M. "British Steel Fire Test3: Reference ABAQUS model using grillage representation for slab" Research report R00-MD10, University of Edinburgh, Department of Civil and Environmental Engineering, February 2000. 
15. Sanad A.M., Lamont S., Usmani A.S and Rotter J.M. "Structural behaviour in fire compartment under different heating regimes - Part 1 (slab thermal gradient)", Fire Safety. Journal Vol 35 No. 2, 99-116, September 2000.

16. Sanad A.M., Lamont S., Usmani A.S and Rotter J.M. "Structural behaviour in fire compartment under different heating regimes - Part 2 (slab mean temperature)", Fire Safety. Journal Vol 35 No. 2, 117-130, September 2000.

17. Sanad A.M., Rotter J.M., Usmani A.S. and O'connor M.A. : "Finite element modelling of fire tests on the Cardington composite building", Proceedings of Interflam' 99, Interscience Communications Ltd . London, No.2-1999, 1045-1056.

18. Structural Fire Engineering Investigation of Broadgate Phase 8 Fire. The Steel Construction Institute, 1991. 